from the finger-tips, especially if associated with resorption of the terminal phalanges, points towards some other disease process, in particular systemic scleroderma.

Flat (macular) polygonal telangiectases on the hands are unusual in patients with Raynaud's phenomenon. In this series they occurred in the patients with systemic scleroderma, and in very small numbers (one to three) in five patients with confirmed primary Raynaud's phenomenon. We believe that in patients with Raynaud's phenomenon, macular telangiectases may be the most valuable early clinical sign of incipient or overt systemic scleroderma if present on the hands, but are of less significance if found on the face alone.

Brachial arteriography is not helpful in distinguishing severe primary Raynaud's phenomenon from early systemic scleroderma. This procedure was performed pre-operatively on four of the patients initially diagnosed as having primary Raynaud's phenomenon who later developed systemic scleroderma. In two the arteriograms were normal, and in two digital-arterial blocks were demonstrated, but there was no specific radiological change to indicate that systemic scleroderma would ensue. Apart from this, arteriography affords a reliable method of diagnosing digital-arterial blockage and was used in the pre-operative assessment of a total of 15 of our patients.

In the 727 patients suffering from systemic scleroderma reviewed by Tuffanelli and Winkelmann (1961) the oesophagus was by far the most commonly involved viscus ( $67 \%$ of patients), and for this reason oesophageal manometry or anti-gravity (supine) barium swallows were performed at follow-up in the patients with primary Raynaud's phenomenon. No unsuspected examples of systemic scleroderma were discovered, and in the borderline group (primary Raynaud's phenomenon with scleroderma-like changes) these investigations did not help to clarify the diagnosis. In those patients with apparent primary Raynaud's phenomenon who developed systemic scleroderma the oesophageal abnormalities merely confirmed our clinical suspicions. Similarly, serological tests (L.E. cells, sheep-cell agglutination, latex fixation, and antinuclear factor) did not help to separate incipient systemic scleroderma from apparent primary Raynaud's phenomenon in this series. These investigations were abnormal in two patients who progressed to systemic scleroderma, but not before the diagnosis was clinically obvious.

A good response to sympathectomy in doubtful cases cannot be taken as confirmatory evidence of primary Raynaud's phenomenon, since improvement after surgery occurred in five of our patients with the slowly evolving variety of systemic scleroderma.

\section{Summary}

Seventy-five patients who had had upper thoracic sympathectomy for Raynaud's phenomenon of the hands 3 to 24 years earlier were reviewed. The pre-operative diagnoses were primary Raynaud's phenomenon in 43, digital-artery thrombosis in 21 , systemic scleroderma in 8 , systemic lupus erythematosus in 2, and dermatomyositis in 1 .

Eight patients apparently suffering from primary Raynaud's phenomenon at the time of operation had developed systemic scleroderma at follow-up, the Raynaud's phenomenon preceding other features of the disease by an interval of from 3 to 20 years.

The late results of sympathectomy were best in digital-artery thrombosis ( $71 \%$ success) and in confirmed primary Raynaud's phenomenon ( $58 \%$ success). The results were poor in patients who had advanced systemic scleroderma at the time of operation and in the three patients who had other connective-tissue disorders, but no dissemination of the condition resulted from operation.

The patients with apparent primary Raynaud's phenomenon who ultimately developed systemic scleroderma responded to sympathectomy; the operative result gave no indication of the true diagnosis. In such patients finger-tip necroses and macular telangiectases on the hands should suggest incipient systemic scleroderma.

We are grateful to Dr. H. J. Wallace for suggesting this study. We thank the physicians and surgeons of St. Thomas's Hospital, and Professor G. W. Taylor, St. Bartholomew's Hospital, for permission to study patients under their care. This work was supported by a grant to one of us (E. N. M. J.) from the St. Thomas's Hospital Endowment Fund.

\section{REFERENCES}

Allen, E. V., Barker, N. W., and Hines, E. A., jun. (1962). Peripheral Vascular Diseases, 3rd ed., p. 137. Saunders, Philadelphia.

- and Brown, G. E. (1932). Amer. f. med. Sci., 183, 187.

Buchanan, J. L., Cranley, J. J., and Linton, R. R. (1952). Surgery, 31, 62.

de Takats, G., and Fowler, E. F. (1962). f. Amer. med. Ass., 179, 1.

Dornhorst, A. C., Harrison, K., and Pierce, J. W. (1954). Lancet, 1, 695. Gifford, R. W., Hines, E. A., jun., and Craig, W. McK. (1958). Circulation, 17, 5 .

Hall, K. V., and Hillestad, L. K. (1960). Angiology, 11, 186

Jablonska, S., Bubnow, B., and Lukasiak, B. (1958). Brit. f. Derm., 70

37.

二- $=$ and Szczepánski, A. (1962). Ibid., 74, 174.

Lewis, T., and Pickering, G. W. (1934). Clin. Sci., 1, 327

Pawlowski, A. (1963). Arch. Derm., 88, 868.

Raynaud, A. G. M (1862). Thèse de Doct. Paris, Rignaux.

- (1874). Arch. gén. Méd., 5, 189.

Tuffanelli, D. L., and Winkelmann, R. K. (1961). Arch. Derm., 84,
Ashby et al. (1964) discussed some of the literature on eosinophilic granuloma of the gastro-intestinal tract in man. They referred to 47 papers which describe a total of 89 cases and stated that, although " the herring parasite" may not be responsible for all these cases, it may well be the causative agent in European territories.

- Assistant Director, Commonwealth Bureau of Helminthology, St.

\section{Literature}

From the literature and original observations on "Eustoma rotundatum," a species provisionally referred to as Pseudanisakis rotundata in this paper, attention should be drawn to the following, which show not only that the account by Ashby et al. is greatly oversimplified but also that there is a dire need for more detailed work on all aspects of the biology of those roundworms, which are said to establish themselves temporarily or 
permanently in man, as abnormal infections with harmful effects, although they originate from cold-blooded vertebrates.

Kuipers et al. (1960a, 1960b) and Thiel et al. (1960) referred to a larval roundworm from the herring as the probable cause of an acute abdominal syndrome in man ; they identified the worm as "Eustoma (=Anacanthocheilus) rotundatum." Thiel (1962), however, indicated that the larval nematodes he and his colleagues had found in the stomach and intestine of man, and which had previously been identified as "Eustoma (= Anacanthocheilus) rotundatum" are now thought to be a species of Anisakis; he therefore proposed the name "anisakiasis" for " herring-worm disease." Vik (1964) found larval nematodes in the stomachs of porpoises caught off Bergen, Norway, and described them as "Anisakis-type larvae"; he stated that his material is identical with that described by Berland (1961) as "Anisakis sp. larva I" and by Thiel et al. (1960) as "Eustoma (Anacanthocheilus) rotundatum." Berland (1961) recorded "Anisakis sp. larva (I)" from 27 species of bony fishes and from the cephalopod Ommatostrephes sagittatus.

The herring, according to Dollfus (1956), harbours a large number of species of helminths, including the following larval roundworms: Contracaecum aduncum, C. spiculigerum, Porrocaecum (Terranova) decipiens, Anisakis sp., Capsularia halecis (=Ascaris harengum), and "Eustoma rotundatum." Our knowledge of these worms is limited, and therefore little emphasis should be given at present to these names, especially in view of the controversy in the literature-for example, Pseudanisakis rotundata is also referred to as "Eustoma rotundatum," while Porrocaecum decipiens is referred to as Terranova decipiens or Phocanema decipiens.

\section{Pseudanisakis rotundata}

In nature $P$. rotundata commonly occurs in a cold-blooded vertebrate ; that is, the adult in the intestine of the elasmobranch fish Raja radiata and the larvae in the flesh and viscera of at least 12 species of teleost fishes, including the herring. So far as we know at present, $R$. radiata may be the main and perhaps the only host of adult $P$. rotundata; but this ray is mainly a northern species, and is not found in the southern North Sea or in the English Channel, and very rarely in the Irish Sea or off the West of Scotland, areas in which herring are caught. It is therefore unreasonable to refer to $P$. rotundata as " the herring parasite."

Thiel (1962) stated that the larvae of Anisakis, which normally occur in the herring, cause slight tissue reactions in the intestines of experimentally infected rabbits when they penetrate for the first time and then rapidly disappear. He also pointed out that when another larva penetrates near a spot where a larva had already entered inflammation appears which strongly resembles that observed in human patients. It has, however, been mentioned above that controversy still exists in the literature on the identification of larval roundworms from fish, including those of Anisakis, Porrocaecum, and Contracaecum. Ashby et al. (1964) are therefore incorrect in suggesting, mainly from the detailed and interesting work carried out by Thiel and his colleagues, that intestinal eosinophilic granuloma in European countries is mainly due to "Eustoma." Furthermore, Myers (1963) fed guinea-pigs with anisakid larvae from fish, and observed that, although they migrated in all directions, they also disappeared completely from the body in about six days. She concluded that it is quite possible that other members of the Anisakidae occurring as larvae in fish, and developing to adults in warm-blooded hosts, are capable of a similar migration. The comments by Ortlepp (1922a, 1922b), and by Sprent and Barrett (1964), also suggest that roundworms from a cold-blooded vertebrate may survive, with harmful effects, in a warm-blooded animal.
From original observations there are reasons for believing that larvae of Pseudanisakis reach a length of only about $3 \mathrm{~mm}$. in the flesh and viscera of some teleost fishes, while those of Anisakis may reach a length of $21-33 \mathrm{~mm}$. The two genera differ in the position of the excretory pore and in other characters. It is therefore surprising that a larval roundworm measuring about $20 \mathrm{~mm}$. and found in the intestine of man should have been originally identified as "Eustoma" and subsequently as Anisakis, especially in view of the contributions by helminthologists including Grainger (1959) who have given valuable information on the identification of the roundworms Contracaecum, Anisakis, and Porrocaecum from bony fishes.

There is one record (Buckley, 1951) of an immature Porrocaecum sp. found wriggling in a person's mouth during the night ; it was suggested that this had probably come from a piece of undercooked fish. Another record (Vitzthum, 1933) refers to "Ascaris capsularia (= Porrocaecum decipiens =Terranova decipiens)" having survived for 10 days after being boiled for 20 minutes in a portion of cod, previously treated with vinegar and salt water; but Ronald (1960), who carried out detailed investigations on the effect of temperature on Terranova decipiens, correctly refutes this statement. Furthermore, in a series of experiments on Porrocaecum, Crampton et al. $(: 260)$ failed to infect beagle pups, postmortem examination of 12 pups given the larvae showing that they were normal with respect to gross pathology. These workers conclude that feeding pups with up to 80 larvae of Porrocaecum does not exert any deleterious effects on weight gains, voluntary feed consumption, feed-utilization efficiency, or general health of the dogs.

\section{Aetiological Agents of Eosinophilic Meningitis}

Rosen et al. (1961) suggested that an outbreak of eosinophilic meningitis in Tahiti was caused by some helminth parasite of a pelagic fish commonly eaten raw in the area ; but Alicata (1962), Alicata and Brown (1962), and Alicata et al. (1963) believed that Angiostrongylus cantonensis, a nematode normally parasitic in rats, with slugs as intermediate hosts, was the causative agent. Galliard (1962) and Anderson et al. (1962), however, pointed out that there was insufficient knowledge of eosinophilic meningitis in man in Tahiti to suggest a helminth aetiology. Alicata (1963) refers to the possible relation of $A$. cantonensis with eosinophilic meningitis, and states that the source of infection is believed to be infected snails and planarians accidentally eaten with improperly washed lettuce or other vegetables. He also stated that, although there is no evidence to support the belief that human infection with the larvae of Angiostrongylus takes place through broken skin, such a mode of infection cannot be disregarded. In Tahiti freshwater prawns become parasitized with the larvae of $A$. cantonensis by eating snails or slugs. Since freshwater prawns are habitually eaten raw in Tahiti they have been considered an important source of human infection in that area; but many persons with the disease in Tahiti have never eaten raw prawns.

The inhabitants of Ponape, location of the first recorded epidemic of eosinophilic meningitis, consume neither raw leaf vegetables nor raw prawns. Alicata and McCarthy (1964) state that the finding of rat lungworm on the island of Rarotonga, in the Pacific, is an additional example of the presence of this parasite in an area where human cases of eosinophilic meningitis are known to occur. Slugs and snails on the island were also infected with the nematode, and so were a few planarians and prawns. They state that on Rarotonga the method of human infection has not yet been ascertained, and that the possibility that lungworm larvae are transmitted to man through other than the presently known carrier hosts (prawns and planarians) remains to be determined. Several other problems in connexion with Angiostrongylus have been referred to 
in the literature. In view of problems of this nature it is essential to reserve judgment on the cause of intestinal eosinophilic granulomata in man in this country rather than suggest that the aetiological agents are larval roundworms from fishes, identifiable to species. So far, the larval stages of roundworms found in fishes have received little critical attention in regard to their taxonomy and ability to survive under normal or abnormal conditions.

It is well known, as Freeman (1964) and others have pointed out, that eosinophilic granulomata can be caused by certain members of the Gnathostomidae, Ancylostomidae, Ascaridae, and the Anisakidae, members of which often occur in large numbers in animals other than fish. In view of this, Ashby et al. (1964) wrongly emphasize the importance of "Eustoma," and give only a passing reference to "the ova or larvae of one of a number of different parasites contaminating animal food products" as another possibility.

\section{Infection in Man}

Ashby et al. suggest that a fishmonger may have become infected by eating pieces of raw kipper and haddock, but they do not emphasize that this must surely be an unusual habit in the British Isles. They state that the comparative rarity of the condition suggests that repeated exposure to infection is necessary, and that an immune state is gradually acquired, the chronic granuloma being a local tissue allergic response. Certain sections of the community, however, are often ideally located for repeated infections-for example, thousands of British trawlermen and other persons connected with the fish trade constantly handle fish viscera heavily parasitized with roundworms but have apparently escaped infection. It is alleged (personal communication with $\mathrm{Mr}$. R. W. Blacker, Fisheries Laboratory, Lowestoft) that in some areas fishermen consume quantities of uncooked fresh liver from cod; but they appear to have escaped infection with roundworms, which are often found in large numbers in the livers of cod and other fish. It is also relevant to mention that millions of housewives also handle fresh fish at regular intervals, and appear to escape infection with fish roundworms ; on the other hand, there is sufficient evidence that housewives in this country, because they handle fresh meat, are much more likely than other members of the household to become infected with the tapeworm Taenia saginata; in this connexion it should be emphasized that the incidence of $T$. saginata in man in Britain is very low. In some areas of the world-for example, in the Far East and in Alaska-it is known that certain people consume large quantities of fish, some of which is eaten raw, but with one exception there is no evidence to show that these people become infected with roundworms from fishes.

Detailed parasitological studies on humans in Japan and Korea were described in two bulletins by Hunter et al. (1951a, 1951b), while Hoeppli (1950) discussed rare forms of human parasitic infections of interest to the physician in China, but none of these three references nor a very large number of other papers reporting on the helminths of man in various regions of the world indicate that roundworms from fishes are harmful to man ; cases of infection of man with Gnathostoma or with Dioctophyme renale are notable exceptions. The cases of human infection reported in Holland were extremely rare exceptions, and a recurrence is unlikely now that it is known why larval roundworms remained alive in some of the herring landed in Holland. Thiel et al. (1960) recommended the gutting of herring immediately on being caught as a simple preventive measure against " herring-worm disease."

Roundworms which may have originated from fishes were found in the intestines of Eskimos examined by Hitchcock (1950), but no harmful effects were described. She reported intestinal protozoa and various helminths, which included ascarid larvae in $10 \%$ of the 192 Eskimos examined in the
Bethel area of Alaska. A taxonomist's report on these ascarid larvae is quoted as follows in Hitchcock's paper. " All appeared to be ascarid larvae-that is, larvae of some nematode belonging to the family Ascarididae. The theoretical possibilities are (1) that the worms are larvae of Ascaris lumbricoides eliminated spontaneously as a result of the development of host resistance or following the use of an anthelmintic, (2) that they are Anisakinae larvae ingested with the flesh of fish and passed from the digestive tract because man is an unsuitable host or because cooking, or freezing, has impaired their viability. One specimen, however, was definitely identifiable to the subfamily Anisakinae, probably to the genus Porrocaecum, and another could with reasonable certainty be determined as a member of the genus Anisakis." Hitchcock comments as follows on the taxonomist's report: "It would seem that the latter possibility is most likely correct, as no Ascaris lumbricoides eggs or adults were observed."

Hitchcock (1951) reported on a similar survey on 376 Eskimos of the Kotzebue area of Alaska, but no ascarid larvae were recorded. She stated that the Eskimos in the Bethel area consume more freshwater fish, since many of the villages were located along the Kuskokwim River. In the Kotzebue area the native food consists of white whale, reindeer, bear, and fish. chiefly of the salt-water variety.

\section{Conclusion}

In view of the above I would suggest that, bearing in mind our methods of cooking, the roundworms found in fishes landed in Britain should be considered harmless to man until definitely proved otherwise by a series of well-controlled experiments, and that further research should be instigated on their biology and taxonomy before they are named as possible agents of disease in man. In view of its normal habitat and of what is known of the physiology of other helminths of elasmobranchs, Pseudanisakis is probably the least important of roundworms in this connexion. Adults of $P$. rotundata from the natural final host are very difficult to identify, and their larvae present additional problems; neither should be identified solely from the reaction they cause.

\section{Summary}

Evidence is given for believing that "Eustoma rotundatum," a parasitic roundworm which is alleged to occur commonly in North Sea herring, may be the least important cause of eosinophilic granulomata in man, and that the ova or larvae of other parasitic worms which often occur in large numbers in animals other than fish may play a far more significant part as aetiological agents of the disease. It is also emphasized that the larval roundworms found embedded in the intestine of man, and thought to have originated from another vertebrate, should not be identified to species or even genus without a careful consideration of the several factors involved in such abnormal infections.

Professor R. T. Leiper, F.R.S., drew my attention to the article by Ashby et al. I should like to thank him and other colleagues at the Commonwealth Bureau of Helminthology, St. Albans, for much constructive criticism in the preparation of this paper. I am also grateful to Dr. H. A. Cole and Mr. R. J. H. Beverton, Fisheries Laboratory, Lowestoft, for reading the manuscript and suggesting improvements.

\section{REFERENCES}

Alicata, J. E. (1962). Can. 7. Zool., 40, 5 (1963). S. Pacif. Comn. tech. Pap., 139, pp. 1-9. and Brown, R. W. (1962). Can. F. Zool. 40, 755 . Loison, G. and Cavallo A Can. F. Zool., 40, 755. Loison, G., and Cavallo, A. (1963). F. Parasit. 49, 156.

Anderson, R. I., Sadun, E. H., Rosen, L., Weinstein, P. P., and Sawyer, T. (1962). \%. Parastit., 48, 15. 
Ashby, B. S., Appleton, P. J., and Dawson, I. (1964). Brit. med. F., 1,

Berland, B. (1961). Sarsia, 2, 1-50.

Buckley, J. J. C. (1951). Trans. roy. Soc. trop. Med. Hyg., Demonstration, 44, 362.

Crampton, E. W., Donefer, E., and Schad, D. J. (1960). 7. Fish. Res. Bd Can. 17, 501 .

Dollfus, R. Ph. (1956). 7. Cons. int. Explor. Mer., 22, 58

Freeman, R. S. (1964). Can. F. Zool., 42, 367.

Galliard, H. (1962). Bull. Soc. Path. exot., 55, 731.

Grainger, J. N. R. (1959). Parasitology, 49, 122.

Grainger, J. N. R. (1959). Parasitology, 49,

Hitchcock, D. J. (1950). 7.

Hoeppli, R. (1950). Chin. med. F., 68, 221.

Hunter, G. W., Ritchie, L. S., and Chang, I. C. (1951a). Japan Logistical Command Bull, No. 2, pp. 1-20.
Kuipers, Pan, C., and Lin, S. (1951b). Ibid., No. 3, pp. 1-29.

Kuipers, F. C., Thiel, P. H. van, and Roskam, E. T. (1960a). Ned. T. Geneesk, 104, 422 .

Rodenburg, W., Wielinga, W. J., and Roskam, R. T. (1960b). Lancet, 2, 1171 .

Myers, B. J. (1963). Can. F. Zool., 41, 147.

Ortlepp, R. J. (1922a). F. trop. Med. Hyg., 25, 97

- (1922b). Lancet, 1, 847 .

Ronald, K. (1960). Can. 7. Zool., 38, 623.

Rosen, L., Laigret, J., and Bories, S. (1961). Amer. F. Hyg., 74, 26.

Rosen, L., Laigret, J., and Bories, S. (1961). Amer. F. Hyg., 74, 26.

Thiel, $P$. H. van (1962). Parasitology, 52, 16

Thiel, P. H. van (1962). Parasitology, 52, 16. . Trop. geogr. Med., 12, 97.

Vik, R. (1964). Can. F. Zool., 42, 513.

Vitzthum, H. G. (1933). S.-B. Ges. naturf. Fr. Berl., 3, 370.

\title{
D-xylose Absorption in Patients with Eczema
}

\author{
LIONEL FRY,* M.D., B.SC., M.R.C.P. ; SAM SHUSTER, † M.B., B.S., PH.D., M.R.C.P. ; \\ R. M. H. MCMINN, $\ddagger$ M.D., PH.D.
}

Brit. med. F., 1965, 1, 967-968

Eczema can be associated with gastro-intestinal malabsorption (Bennett et al., 1932 ; Thaysen, 1932 ; Cooke et al., 1953 ; Badenoch, 1960 ; Wells, 1962), and may indeed be the first or presenting feature of the intestinal disorder (Cooke, 1952; Wells, 1962). We have at present no idea what the incidence of intestinal malabsorption might be in patients with eczema ; and hence we do not know whether patients with eczema should undergo screening tests for the diagnosis of intestinal malfunction. For this reason, in a previous study, urinary formiminoglutamic acid (figlu) excretion was measured after a dose of L-histidine (Knowles et al., 1963). It was shown that this test is invalid in patients with skin disease, about one-third of whom had an increased urinary excretion of figlu in the absence of intestinal malabsorption; and this is associated with a low plasma folic-acid concentration (Chanarin, Marks, and Shuster, unpublished observations).

The urinary excretion of the pentose $D$-xylose after an oral dose of $25 \mathrm{~g}$. is widely employed as a screening test for intestinal malabsorption (Fourman, 1948 ; Gardner and Perez-Santiago, 1956 ; Benson et al., 1957 ; Christiansen et al., 1959 ; Fowler and Cooke, 1960), and we therefore applied it to assessing the incidence of intestinal malabsorption in patients with eczema.

\section{Materials and Methods}

Patients Studied.-Seventy male and female patients were investigated, all under 65 years of age. The object was to study every patient admitted with eczema to one in-patient skin unit (St. John's Hospital for Diseases of the Skin) over a period of several months. The group included patients with all types of eczema, hospital admission being for severity or special investigation. The first 50 patients were consecutive admissions of eczema, but unfortunately a number of the patients admitted subsequently were not studied and the remaining 20 patients were not consecutive. As there was no obvious difference in the findings the results are presented as one group.

Procedure.-Food and fluid were withheld from the patients for at least eight hours overnight. They had no breakfast, and, after voiding, each patient took $25 \mathrm{~g}$. of $\mathrm{D}$-xylose dissolved in $250 \mathrm{ml}$. of water, followed by another $250 \mathrm{ml}$. of water. The urine passed in the next five hours was collected. A sample of venous blood was taken two hours after the ingestion of

* Registrar, Department of Dermatology, St. Thomas's Hospital, London. † Professor of Dermatology, University of Newcastle upon Tyne. ‡ Reader in Anatomy, King's College, London. the D-xylose. Blood-and-urine xylose was measured by the method of Roe and Rice (1948). On five of the patients the whole procedure was repeated several days later. Smallintestinal biopsy was performed on a number of patients (see below).

\section{Results}

The five-hour urinary excretion of xylose was less than $4.1 \mathrm{~g}$., the lower limit of the normal, in 11 of the patients (see Fig.). The test was repeated in 5 of these 11 patients, and in all instances the five-hour urinary excretion of xylose was again less than $4.1 \mathrm{~g}$. The plasma xylose concentrations were, however, above the level expected in patients with intestinal malabsorption (see Fig.). A small-intestinal biopsy was taken in 10 of the 11 patients and the mucosa was normal in all 10 . It was noted that each of these 11 patients had widespread skin disease.

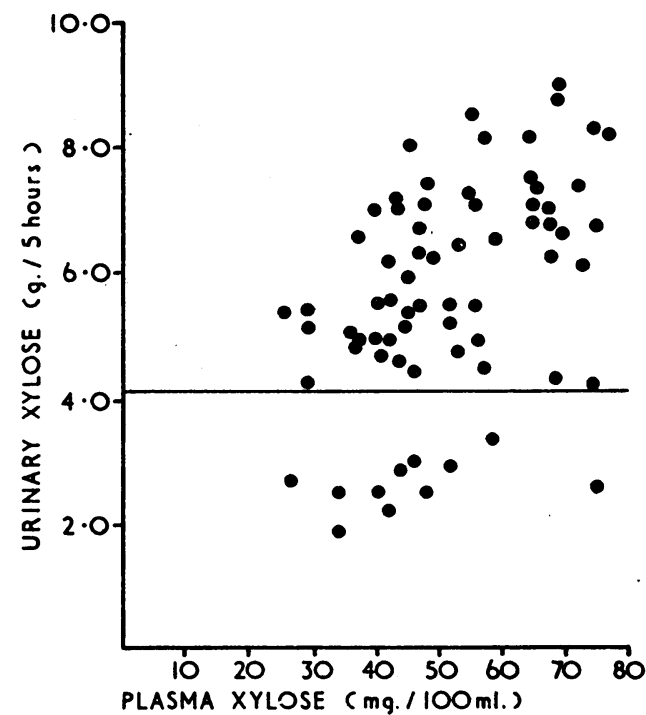

Urinary excretion of xylose (g./5 hours) and plasma xylose concentration at two hours.

\section{Discussion}

Normal subjects excrete in the urine $4.1 \mathrm{~g}$. or more of a 25 -g. oral dose of D-xylose in five hours (Fourman, 1948 ; Benson et al., 1957 ; Christiansen et al., 1959 ; Fowler and Cooke, 